\title{
Experimental and theoretical study of the electronic structures of intermetallic compounds and alloys containing $\mathrm{Fe}$ or $\mathrm{Ni}$
}

\author{
Li-Shing Hsu $^{\text {a,* }}$, Y.-K. Wang ${ }^{\text {b }}$, G.Y. Guo ${ }^{\text {b }}$ \\ a Department of Physics, National Chang-Hua University of Education, Chang-Hua 50058, Taiwan, ROC \\ ${ }^{\mathrm{b}}$ Department of Physics, National Taiwan University, Taipei 107, Taiwan, ROC
}

Received 20 October 2003; received in revised form 14 November 2003; accepted 20 November 2003

\begin{abstract}
The electronic structures of two groups of intermetallic compounds and alloys containing Fe, V, or Ni are studied by X-ray absorption near-edge spectra (XANES) at the Fe, $\mathrm{V}$, and $\mathrm{Ni} \mathrm{L}_{2,3}$ edges and the $\mathrm{Fe} \mathrm{K}$ edge. The XANES spectra are compared with those calculated with two theoretical methods. The differences in the XANES spectra of compounds containing Ni calculated by these two methods are discussed. Except for NiGa, a reasonable good agreement between theory and experiment was found for all materials. The density of states at the Fermi energy at different atomic sites are also calculated for the compounds and alloys containing Fe.

(C) 2003 Elsevier B.V. All rights reserved.
\end{abstract}

PACS: 71.15.-m; 78.40.-q; 71.20.-b

Keywords: X-ray absorption; Corrosion-resistant; Intermetallics

\section{Introduction}

Intermetallic compounds and alloys that contain transition metals and a group-III metal display interesting mechanical, electronic, magnetic, transport, and optical properties. In this paper, X-ray absorption near-edge spectra (XANES) at the $\mathrm{Fe}, \mathrm{V}$, and $\mathrm{Ni}_{2,3}$ edges of two groups of intermetallic compounds and alloys were measured and compared with theoretical XANES spectra. These two groups of samples are: (1) $\mathrm{Fe}_{3} \mathrm{Al}, \mathrm{Fe}_{2} \mathrm{VAl}$, and $\mathrm{Fe}_{2-x} \mathrm{~V}_{1+x} \mathrm{Ga}(x=0,0.02,0.05$, and 0.11), and (2) $\mathrm{Ni}_{3} \mathrm{Al}, \mathrm{Ni}_{3} \mathrm{Ga}, \mathrm{Ni}_{3} \mathrm{In}$, and $\mathrm{NiGa}$. The $\mathrm{Fe}$ K-edge XANES spectra of $\mathrm{Fe}_{1.98} \mathrm{~V}_{1.02} \mathrm{Al}$ and $\mathrm{Fe}_{2-x} \mathrm{~V}_{1+x} \mathrm{Ga}$ $(x=0.02,0.05$, and 0.11$)$ are also reported and compared with theoretical spectra in this paper. The crystal structures and Curie temperatures of the seven stoichiometric compounds are listed in Table 1. While $\mathrm{Fe}_{3} \mathrm{Al}$ is classified as a ferromagnetic metal, the Heusler-type compounds $\mathrm{Fe}_{2} \mathrm{VAl}$ and $\mathrm{Fe}_{2} \mathrm{VGa}$ are characterized as semimetals due to a deep pseudogap formation right at the Fermi energy $\left(E_{\mathrm{F}}\right)$. The presence of this sharp pseudogap of the size of several tenth

\footnotetext{
* Corresponding author. Tel.: +886-4-723-2105/3305; fax: +886-4-721-1153.

E-mail address: phhsu@cc.ncue.edu.tw (L.-S. Hsu).
}

of an $\mathrm{eV}$ was predicted by several theoretical band-structure calculations and further confirmed by various experimental measurements [1]. When one replaces $\mathrm{Fe}(\mathrm{I})$ atoms by $\mathrm{V}$ atoms in $\mathrm{Fe}_{2} \mathrm{VAl}$ and $\mathrm{Fe}_{2} \mathrm{VGa}$, the low-temperature electrical resistivity and thermoelectric power increase drastically [1]. This thermopower enhancement for $\mathrm{Fe}_{2} \mathrm{VAl}$ is caused by a sharp rise of the density of state (DOS) in both sides of the pseudogap [2]. This observation suggests that both systems contain fewer charge carriers and behave semimetallically. Tunability of the physical characteristic of $\mathrm{Fe}_{2} \mathrm{VAl}$ by doping $\mathrm{V}$ at the specific Fe site is also found in its magnetic and transport properties [3]. Moreover, $\mathrm{Fe}_{2} \mathrm{VAl}$ and $\mathrm{Fe}_{2} \mathrm{VGa}$ have been reported to be possible $3 \mathrm{~d}$ heavy-fermion materials $[3,4]$. The ordered compounds $\mathrm{Fe}_{3} \mathrm{Al}, \mathrm{Ni}_{3} \mathrm{Al}$, and $\mathrm{Ni}_{3} \mathrm{Ga}$ have many unique properties that make them attractive for high-temperature, corrosion-resistant, and super-hard applications, while NiGa possesses complicated defect structure and has been suggested as a potential conducting contact to III-V semiconductors [5].

Experimental and theoretical $\mathrm{Fe}$ and $\mathrm{V}$ K-edge XANES spectra of $\mathrm{Fe}_{3} \mathrm{Al}, \mathrm{Fe}_{2} \mathrm{VAl}$, and $\mathrm{Fe}_{2} \mathrm{VGa}$ were published recently [6,7]. To our knowledge, no $\mathrm{Fe}$ and $\mathrm{V} \mathrm{L}_{2,3}$-edge XANES spectra can be found in the literature for these three compounds and the disordered alloys $\mathrm{Fe}_{2-x} \mathrm{~V}_{1+x} \mathrm{X}(\mathrm{X}$ : $\mathrm{Al}$, 
Table 1

Crystal structures and Curie temperatures $\left(T_{\mathrm{C}}\right)$ for $\mathrm{Ni}_{3} \mathrm{Al}, \mathrm{Ni}_{3} \mathrm{Ga}, \mathrm{Ni}_{3} \mathrm{In}$, $\mathrm{NiGa}, \mathrm{Fe}_{3} \mathrm{Al}, \mathrm{Fe}_{2} \mathrm{VAl}$, and $\mathrm{Fe}_{2} \mathrm{VGa}$

\begin{tabular}{llc}
\hline Material & Crystal structure & $T_{\mathrm{C}}(\mathrm{K})$ \\
\hline $\mathrm{Ni}_{3} \mathrm{Al}$ & $\mathrm{L}_{2}$ & 41.5 \\
$\mathrm{Ni}_{3} \mathrm{Ga}$ & $\mathrm{L}_{2}$ & \\
$\mathrm{Ni}_{3} \mathrm{In}$ & $\mathrm{L}_{2}$ & \\
$\mathrm{NiGa}$ & $\mathrm{B} 2$ & 713 \\
$\mathrm{Fe}_{3} \mathrm{Al}$ & $\mathrm{D} 0_{3}$ & \\
$\mathrm{Fe}_{2} \mathrm{VAl}$ & $\mathrm{L} 2_{1}$ & \\
$\mathrm{Fe}_{2} \mathrm{VGa}$ & $\mathrm{L} 2_{1}$ & \\
\hline
\end{tabular}

$\mathrm{Ga}$. Experimental $\mathrm{Ni} \mathrm{L}_{2,3}$-edge and $\mathrm{Al}$ and $\mathrm{Ni} \mathrm{K}$-edge XANES spectra of $\mathrm{Ni}_{3} \mathrm{Al}$, [8-14] $\mathrm{Ni}_{3} \mathrm{Ga}$, [9-11,13-15] $\mathrm{Ni}_{3} \mathrm{In},[11,13,14,16]$ and $\mathrm{NiGa}[11,13,15]$ have been reported previously. The $\mathrm{Ni} \mathrm{L}_{2,3}$ near-edge structures of $\mathrm{Ni}_{3} \mathrm{Al}$ were also measured by electron-energy-loss spectroscopy $[17,18]$. Theoretical analyses of the Ni L2,3-edge and $\mathrm{Al}$ and $\mathrm{Ni} \mathrm{K}$-edge XANES spectra have been performed on $\mathrm{Ni}_{3} \mathrm{Al}$, [10-14] $\mathrm{Ni}_{3} \mathrm{Ga}$, [10,11,13,14] $\mathrm{Ni}_{3} \mathrm{In}$, $[11,13,14,16]$ and NiGa $[11,13]$ using several methods. The purpose of this paper is to systematically study the electronic structures of a series of technologically interesting intermetallic compounds and alloys, and to compare with available experimental and theoretical results. The total and site-decomposed DOSs at $E_{\mathrm{F}}\left(n\left(E_{\mathrm{F}}\right)\right)$ of the Heusler-type compounds and alloys are also calculated. We note that very few studies were performed on the doped alloys $\mathrm{Fe}_{2-x} \mathrm{~V}_{1+x} \mathrm{Al}$ and $\mathrm{Fe}_{2-x} \mathrm{~V}_{1+x} \mathrm{Ga}$. Not many reports are found for $\mathrm{Ni}_{3} \mathrm{In}$ and $\mathrm{NiGa}$, either.

This paper is organized as follows. In Section 2 the experimental and the theoretical methods are described. In Section 3 the results and discussion are presented. The conclusions of this work are contained in Section 4.

\section{Methods}

\subsection{Experimental methods}

Preparation and characterization of polycrystalline samples of the Fe or Ni intermetallic compounds and alloys were reported previously $[1,7,8,19]$. The XANES experiments on $\mathrm{Ni} \mathrm{L}_{2,3}, \mathrm{Fe}$ and $\mathrm{V} \mathrm{L}_{2,3}$, and $\mathrm{Fe} \mathrm{K}$ edges were carried out on beam lines 12A, 15A, and 15B, respectively, at the National Synchrotron Radiation Research Center (NSRRC), Taiwan. The XANES spectra were collected at room temperature by recording the total yield of secondary electrons at beam lines $12 \mathrm{~A}$ and $15 \mathrm{~A}$ and the fluorescence yield at beam line $15 \mathrm{~B}$. We note that the XANES spectra taken by using the fluorescence-yield mode is more bulk sensitive than those taken by the using the total-electron-yield mode. Standard $5 \mu \mathrm{m}$ thick Fe, V, and Ni foils were used as a reference for energy calibration and their XANES data were also used as reference spectra. The photon flux was obtained simultaneously by measuring the current of a $\mathrm{Au}$ mesh located near the exit slit of the monochromator and used for normalization of the XANES spectra. For the Fe and $\mathrm{V} \mathrm{L}_{2,3}$-edge XANES measurements, the samples were scraped with a diamond file and annealed to $500{ }^{\circ} \mathrm{C}$ until photoemission spectra showed no $\mathrm{O}$ and $\mathrm{C}$ contamination on the sample surfaces. Since $\mathrm{Al}_{2} \mathrm{O}_{3}$ cannot be completely removed from the surfaces of the alloys $\mathrm{Fe}_{2-x} \mathrm{~V}_{1+x} \mathrm{Al}(x=$ $0.02,0.05$, and 0.11$)$, we thus only report here the XANES spectra of the $\mathrm{Fe}_{2-x} \mathrm{~V}_{1+x} \mathrm{Ga}(x=0,0.02,0.05$, and 0.11$)$ compound and alloys. On the other hand, clean surfaces can be obtained by ion-bombardment and subsequent annealing to $500{ }^{\circ} \mathrm{C}$ for $\mathrm{Ni}_{3} \mathrm{Al}, \mathrm{Ni}_{3} \mathrm{Ga}, \mathrm{Ni}_{3} \mathrm{In}$, and $\mathrm{NiGa}$. The metalloid deficiency after cyclic Ar-ion sputtering and annealing ranges from 5 to $25 \%$ for these four intermetallic compounds [11].

\subsection{Theoretical methods}

The theoretical XANES spectra of these intermetallic compounds and alloys are calculated using two methods. The first is the all-electron full-potential linear augmentedplane-wave (FLAPW) method, [20] and the second is the multiple scattering (MS) method [21]. Details of these two calculations were published previously $[6,11,13,16]$. The FLAPW calculation is based on first-principles density functional theory with the generalized gradient approximation (GGA) to the exchange-correlation potential. We find that using the GGA is essential to bring the calculated lattice constants and bulk moduli of these compounds into good agreement with the experimental values. We note that GGA is more accurate than local spin-density approximation in calculating the electronic structures of $\mathrm{Fe}_{2} \mathrm{VAl}$ and $\mathrm{Fe}_{2} \mathrm{VGa}$ $[4,6]$. The FLAPW calculations are done for the paramagnetic or ferromagnetic state for the $\mathrm{Fe}, \mathrm{V}$, or $\mathrm{Ni} \mathrm{L}_{2,3}$-edge and $\mathrm{Fe} \mathrm{K}$-edge XANES spectra of these materials. The effect of $\mathrm{V}$ substitution of the $\mathrm{Fe}(\mathrm{I})$ atoms was taken into account by the virtual-crystal approximation (VCA) in which the $\mathrm{V}-\mathrm{Fe}(\mathrm{I})$ sites were occupied by virtual atoms whose atomic number $(Z)$ is $Z=(1-x / 2) Z(\mathrm{Fe})+(x / 2) Z(\mathrm{~V})$. The VCA has been found to be applicable for many metallic alloys with similar atomic numbers [22,23]. The MS method is based on a self-consistent-field, single-electron, ab-initio real space Green's function code FEFF8. The MS calculations are performed in the absence of a core hole for the $\mathrm{Ni} \mathrm{L}_{2,3}$-edge XANES spectra of $\mathrm{Ni}_{3} \mathrm{Al}, \mathrm{Ni}_{3} \mathrm{Ga}$, $\mathrm{Ni}_{3} \mathrm{In}$, and NiGa. These spectra are compared with those calculated by the FLAPW method.

\section{Results and discussions}

\subsection{Fe and $V L_{2,3}$-edge XANES spectra of $\mathrm{Fe}_{3} \mathrm{Al}, \mathrm{Fe}_{2} \mathrm{VAl}$, and $\mathrm{Fe}_{2-x} \mathrm{~V}_{1+x} \mathrm{Ga}(x=0,0.02,0.05$, and 0.11$)$}

The experimental (open circles) and theoretical (solid line) XANES spectra of $\mathrm{Fe} \mathrm{L}_{2,3}$ edges for $\mathrm{Fe}_{3} \mathrm{Al}, \mathrm{Fe}_{2} \mathrm{VAl}$, 


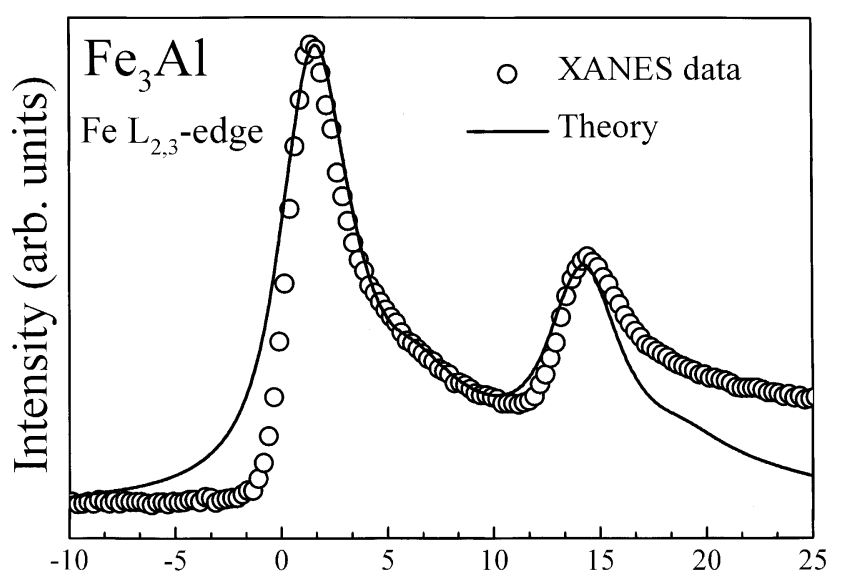

(a)
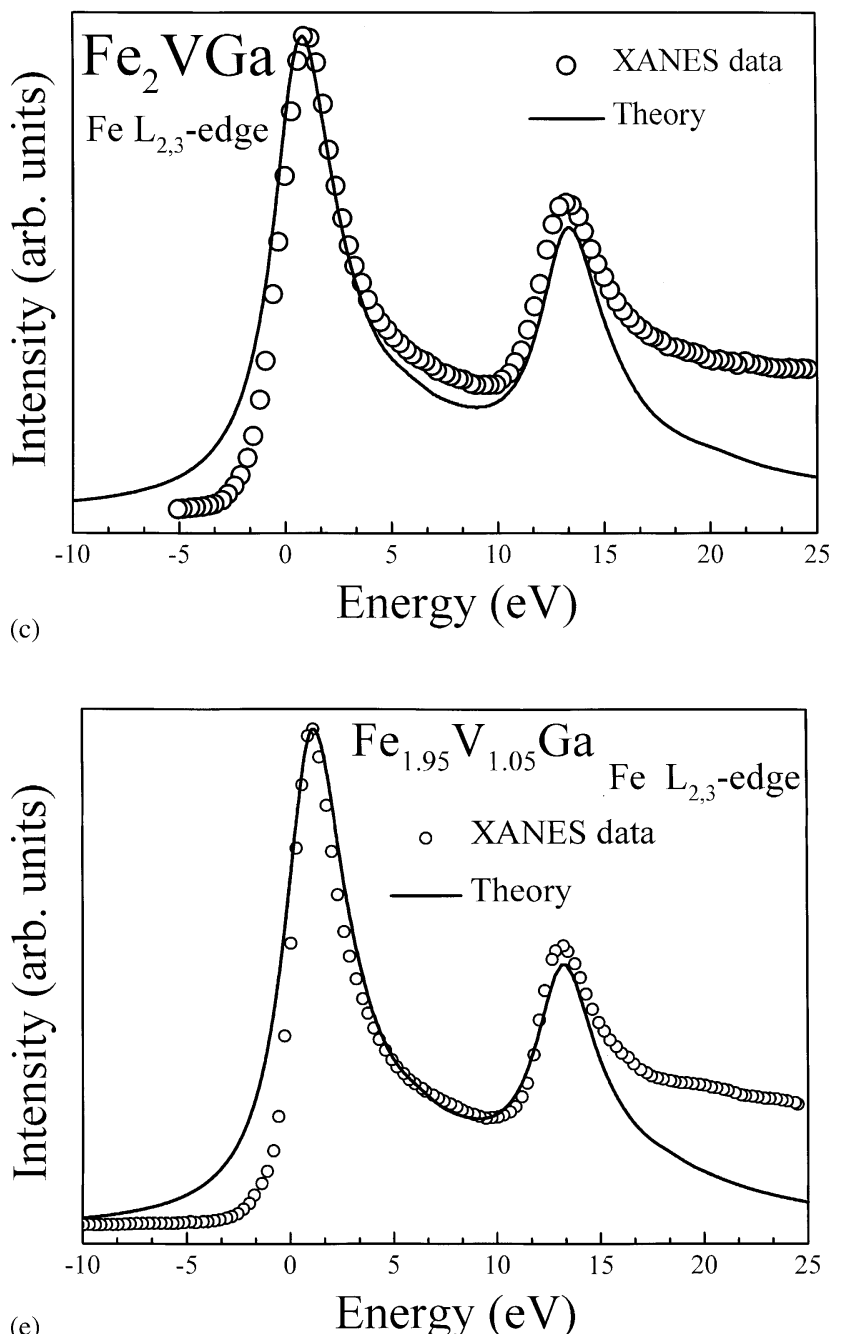
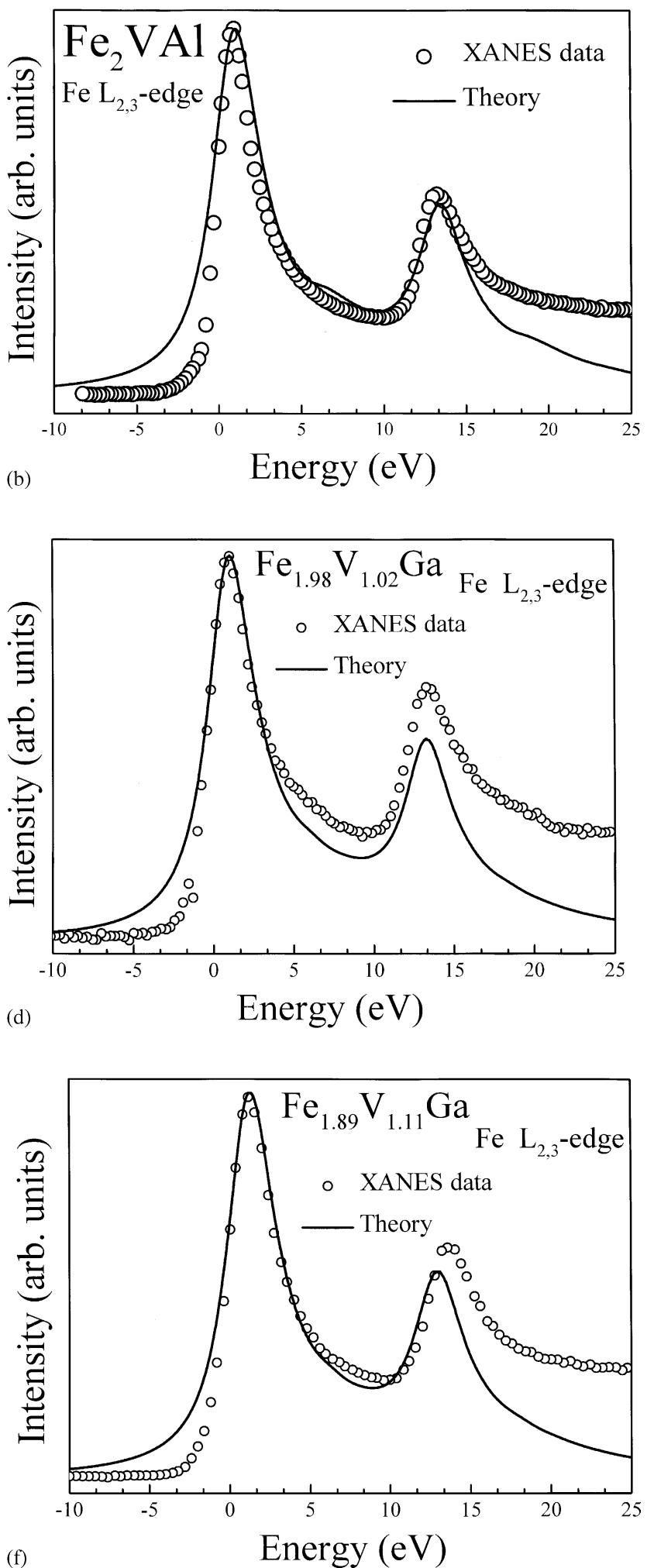

Fig. 1. The experimental $\left(\mathrm{O}\right.$ ) and theoretical (一) Fe $\mathrm{L}_{2,3}$-edge XANES spectra for (a) $\mathrm{Fe}_{3} \mathrm{Al}$, (b) $\mathrm{Fe}_{2} \mathrm{VAl}$, (c) $\mathrm{Fe}_{2} \mathrm{VGa}$, (d) $\mathrm{Fe}_{1.98} \mathrm{~V}_{1.02} \mathrm{Ga}_{\text {, (e) }} \mathrm{Fe}_{1.95} \mathrm{~V}_{1.05} \mathrm{Ga}_{\text {, }}$ and (f) $\mathrm{Fe}_{1.89} \mathrm{~V}_{1.11} \mathrm{Ga}$. 

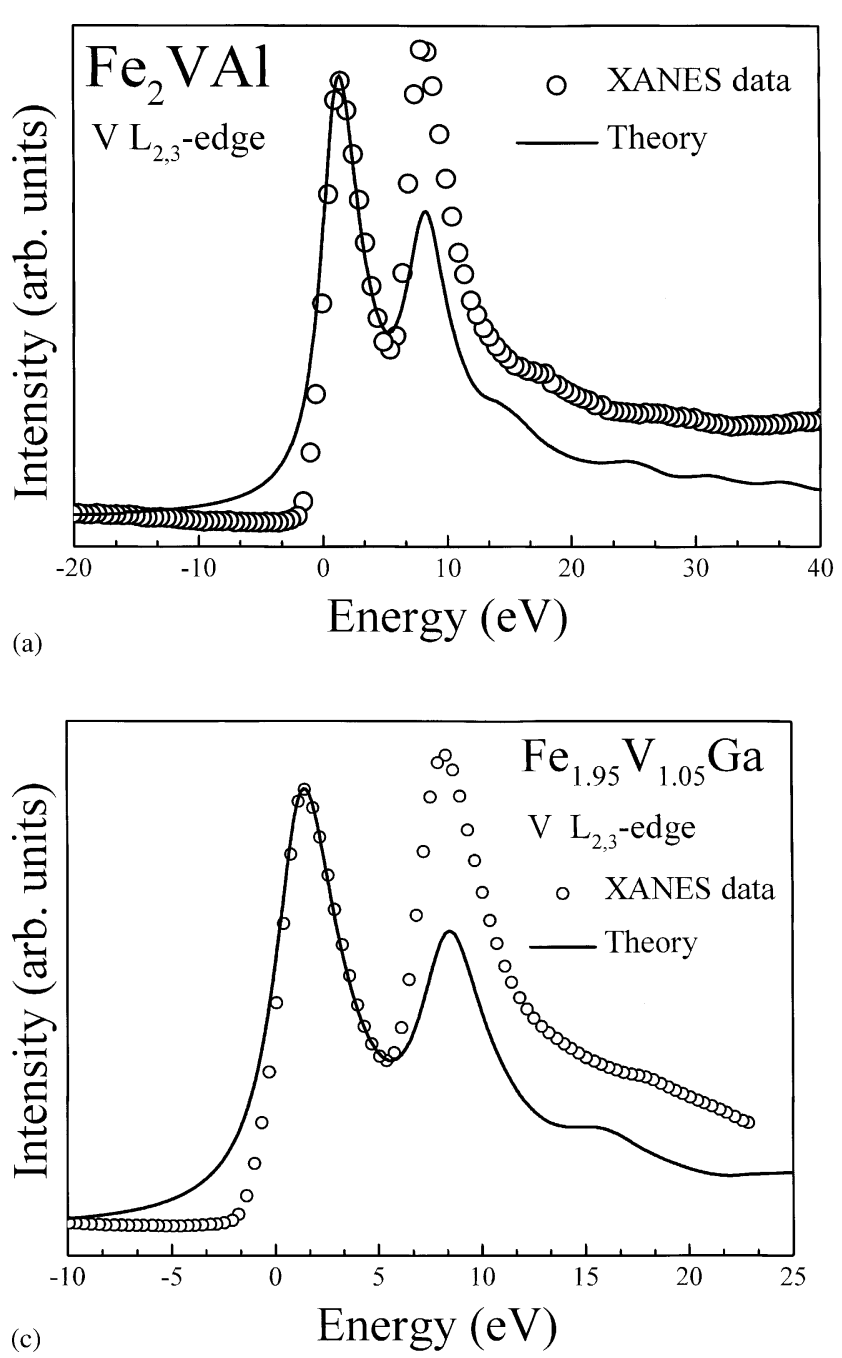
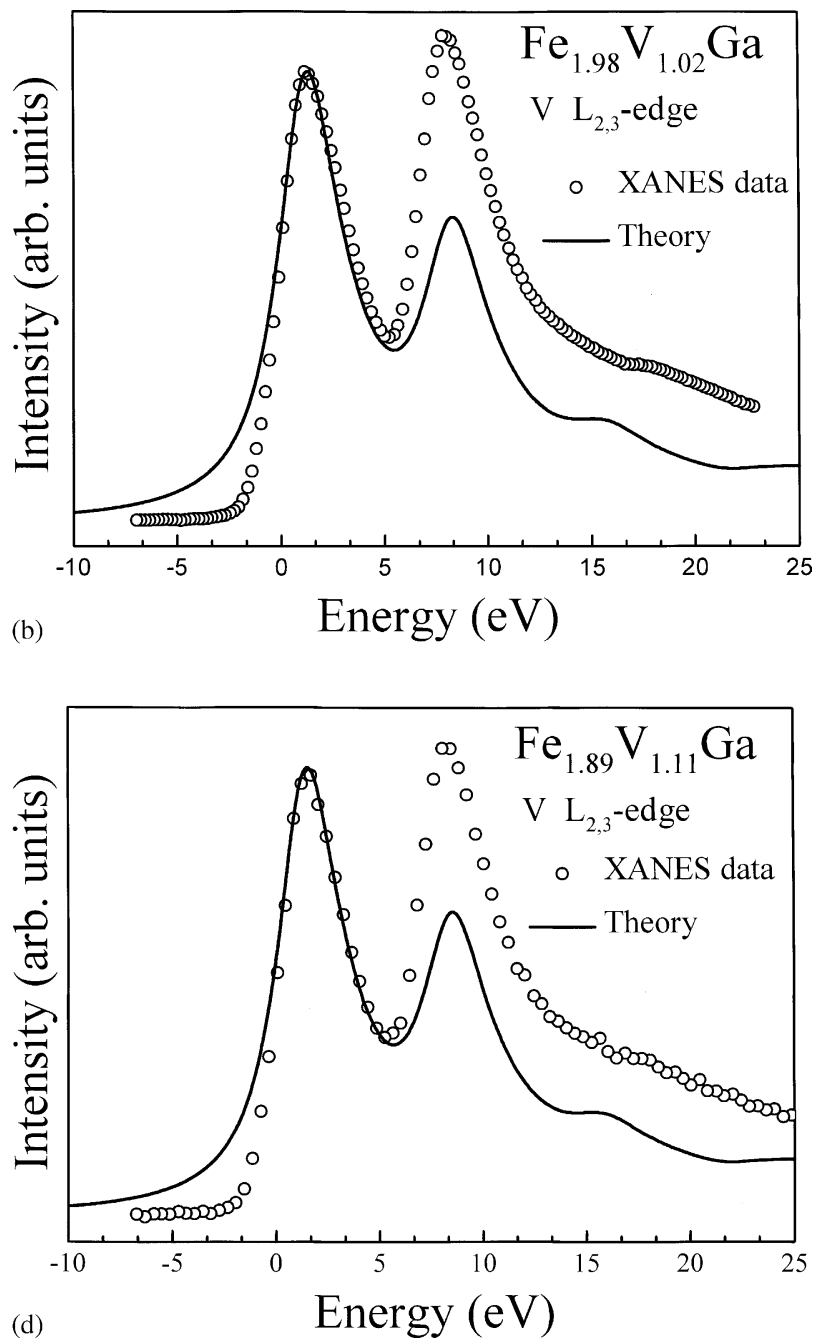

(d)

Fig. 2. Same as in Fig. 1, except for $\mathrm{V} \mathrm{L}_{2,3}$-edge for (a) $\mathrm{Fe}_{2} \mathrm{VAl}$, (b) $\mathrm{Fe}_{1.98} \mathrm{~V}_{1.02} \mathrm{Ga}$, (c) $\mathrm{Fe}_{1.95} \mathrm{~V}_{1.05} \mathrm{Ga}$, and (d) $\mathrm{Fe}_{1.89} \mathrm{~V}_{1.11} \mathrm{Ga}_{\text {. }}$

and $\mathrm{Fe}_{2-x} \mathrm{~V}_{1+x} \mathrm{Ga}(x=0,0.02,0.05$, and 0.11$)$ are shown in Fig. 1a-f, respectively. The XANES spectrum for $\mathrm{Fe}_{3} \mathrm{Al}$ is obtained from the spin-polarized calculation, while those for other materials are obtained from paramagnetic calculations. Those of $\mathrm{V} \mathrm{L}_{2,3}$ edges for $\mathrm{Fe}_{2} \mathrm{VAl}$ and $\mathrm{Fe}_{2-x} \mathrm{~V}_{1+x} \mathrm{Ga}$ $(x=0.02,0.05$, and 0.11$)$ are shown in Fig. 2a-d, respectively. The theoretical spectra were calculated using the FLAPW method. The zero energy corresponds to the inflection point of the respective $\mathrm{Fe}$ or $\mathrm{V} \mathrm{L}_{3}$ absorption edge (706.8 and $512.1 \mathrm{eV}$, respectively). The experimental data were normalized to the theoretical spectra at the peak of the Fe or $\mathrm{V} \mathrm{L}_{3}$ edge. The agreement between theory and experiment for the $\mathrm{Fe}_{2,3}$-edge XANES spectra is best for $\mathrm{Fe}_{3} \mathrm{Al}$ and $\mathrm{Fe}_{2} \mathrm{VAl}$, good for $\mathrm{Fe}_{2} \mathrm{VGa}$ and $\mathrm{Fe}_{1.95} \mathrm{~V}_{1.05} \mathrm{Ga}$, and worse for $\mathrm{Fe}_{1.98} \mathrm{~V}_{1.02} \mathrm{Ga}$ and $\mathrm{Fe}_{1.89} \mathrm{~V}_{1.11} \mathrm{Ga}$; while it is worse for the $\mathrm{V} \mathrm{L}_{2,3}$-edge spectra for $\mathrm{Fe}_{2} \mathrm{VAl}$ and $\mathrm{Fe}_{2-x} \mathrm{~V}_{1+x} \mathrm{Ga}(x=$ $0.02,0.05$, and 0.11). The decrease in intensity above the Fe or $\mathrm{V} \mathrm{L}_{2}$-edge peak is due to the finite-sized, linearized energy-dependent basis sets in the muffin-tin spheres used in the FLAPW calculation. This effect may also cause the decrease of the theoretical Fe and $\mathrm{V} \mathrm{L}_{2}$-edge peak height for $\mathrm{Fe}_{2-x} \mathrm{~V}_{1+x} \mathrm{Ga}(x=0.02$ and 0.11$)$ and the four materials shown in Fig. 2, respectively. Another source of error is that the GGA eigenvalues are not the true excitations of the XANES spectra, and the error in peak position is comparable to the self-energy correction between GGA and more sophisticated methods such as GW [24]. The third source of error may come from the use of VCA approximation for the $\mathrm{Fe}_{2-x} \mathrm{~V}_{1+x} \mathrm{Ga}$ alloys.

\subsection{Fe and $V$ K-edge XANES spectra of $\mathrm{Fe}_{1.98} V_{1.02} \mathrm{Al}$ and $\mathrm{Fe}_{2-x} V_{1+x} \mathrm{Ga}(\mathrm{x}=0.02,0.05$, and 0.11)}

We performed both the spin-polarized and the non-spinpolarized calculations for these alloys, no difference in total energy was found between these two calculations. Thus, these four materials are nonmagnetic and the theoretical XANES spectra calculated by the FLAPW method of the paramagnetic state are used for comparing with the experimental ones. The theoretical and experimental lattice constants of these alloys are shown in the third column in Table 2. Slight increase in the lattice constants is found 
Table 2

Lattice constant $a$, total density of states at the Fermi energy $n\left(E_{\mathrm{F}}\right)$, and bulk modulus $\mathrm{B}$ for $\mathrm{Fe}_{2} \mathrm{VAl}, \mathrm{Fe}_{2} \mathrm{VGa}, \mathrm{Fe}_{2-x} \mathrm{~V}_{1+x} \mathrm{Al}$, and $\mathrm{Fe}_{2-x} \mathrm{~V}_{1+x} \mathrm{Ga}$ $(x=0.02,0.05$, and 0.11$)$

\begin{tabular}{lllll}
\hline Material & & $a(\AA)$ & $n\left(E_{\mathrm{F}}\right)$ (states/eV cell) & $B$ (Mbar) \\
\hline $\mathrm{Fe}_{2} \mathrm{VAl}$ & Para & 5.712 & 0.18 & 2.12 \\
& Exp. & 5.76 & & \\
$\mathrm{Fe}_{1.98} \mathrm{~V}_{1.02} \mathrm{Al}$ & Para. & 5.713 & 0.629 & 2.121 \\
& Exp. & 5.763 & & 2.117 \\
$\mathrm{Fe}_{1.95} \mathrm{~V}_{1.05} \mathrm{Al}$ & Para. & 5.715 & 1.776 & \\
& Exp. & 5.763 & & 2.114 \\
$\mathrm{Fe}_{1.89} \mathrm{~V}_{1.11} \mathrm{Al}$ & Para. & 5.720 & 3.287 & 2.14 \\
& Exp. & 5.763 & & 2.141 \\
$\mathrm{Fe}_{2} \mathrm{VGa}$ & Para. & 5.726 & 0.28 & \multirow{2}{*}{2.141} \\
$\mathrm{Fe}_{1.98} \mathrm{~V}_{1.02} \mathrm{Ga}$ & Exp. & 5.77 & & \\
$\mathrm{Fe}_{1.95} \mathrm{~V}_{1.05} \mathrm{Ga}$ & Para. & 5.726 & 0.436 & 2.140 \\
$\mathrm{Fe}_{1.89} \mathrm{~V}_{1.11} \mathrm{Ga}$ & Para. & 5.776 & & \\
& Exp. & 5.727 & 0.894 & \\
\hline
\end{tabular}

Para. and Exp. represent theoretical paramagnetic and experimental values, respectively. as $\mathrm{V}$ atoms substitute into the $\mathrm{Fe}(\mathrm{I})$ sites. For $\mathrm{Fe}_{2} \mathrm{VAl}$ and $\mathrm{Fe}_{2} \mathrm{VGa}$, doping $\mathrm{V}$ atoms at the $\mathrm{Fe}(\mathrm{I})$ positions results in lower total energy than doping $\mathrm{V}$ atoms at both the $\mathrm{Fe}(\mathrm{I})$ and Fe(II) positions. This is consistent with the well-known site-selectivity property of the Heusler-type compounds, and was confirmed theoretically for $\mathrm{Fe}_{2} \mathrm{VSi}$ [3]. Since $\mathrm{Fe}(\mathrm{I})$ is less electronegative than Fe(II), the Coulomb energy of the crystal lattice will be reduced if $\mathrm{Fe}(\mathrm{I})$ is replaced by a less electronegative element V. This explains the observed site selectivity of the Heusler-type compounds.

The experimental (open circles) and theoretical (solid lines) XANES spectra of $\mathrm{Fe} \mathrm{K}$ edge for $\mathrm{Fe}_{1.98} \mathrm{~V}_{1.02} \mathrm{Al}$, $\mathrm{Fe}_{1.98} \mathrm{~V}_{1.02} \mathrm{Ga}, \mathrm{Fe}_{1.95} \mathrm{~V}_{1.05} \mathrm{Ga}$, and $\mathrm{Fe}_{1.89} \mathrm{~V}_{1.11} \mathrm{Ga}$ are depicted in Fig. 3a-d, respectively. Also shown in Fig. 3 are the Fe p partial DOS (dots) convoluted by the experimental resolution of $1 \mathrm{eV}$ for these alloys. The corresponding XANES spectra of $\mathrm{V} \mathrm{K}$ edge and $\mathrm{V} p$ partial DOS for these four alloys are depicted in Fig. 4a-d, respectively. The maxima of the experimental XANES spectra in Figs. 3 and 4, which correspond to $\mathrm{Fe}$ or $\mathrm{V}$ 1s to $\mathrm{ep}$ transitions, coincide with the peaks in the $\mathrm{Fe}$ and $\mathrm{V}$ p partial DOS curves, respectively. The zero energies in Figs. 3 and 4
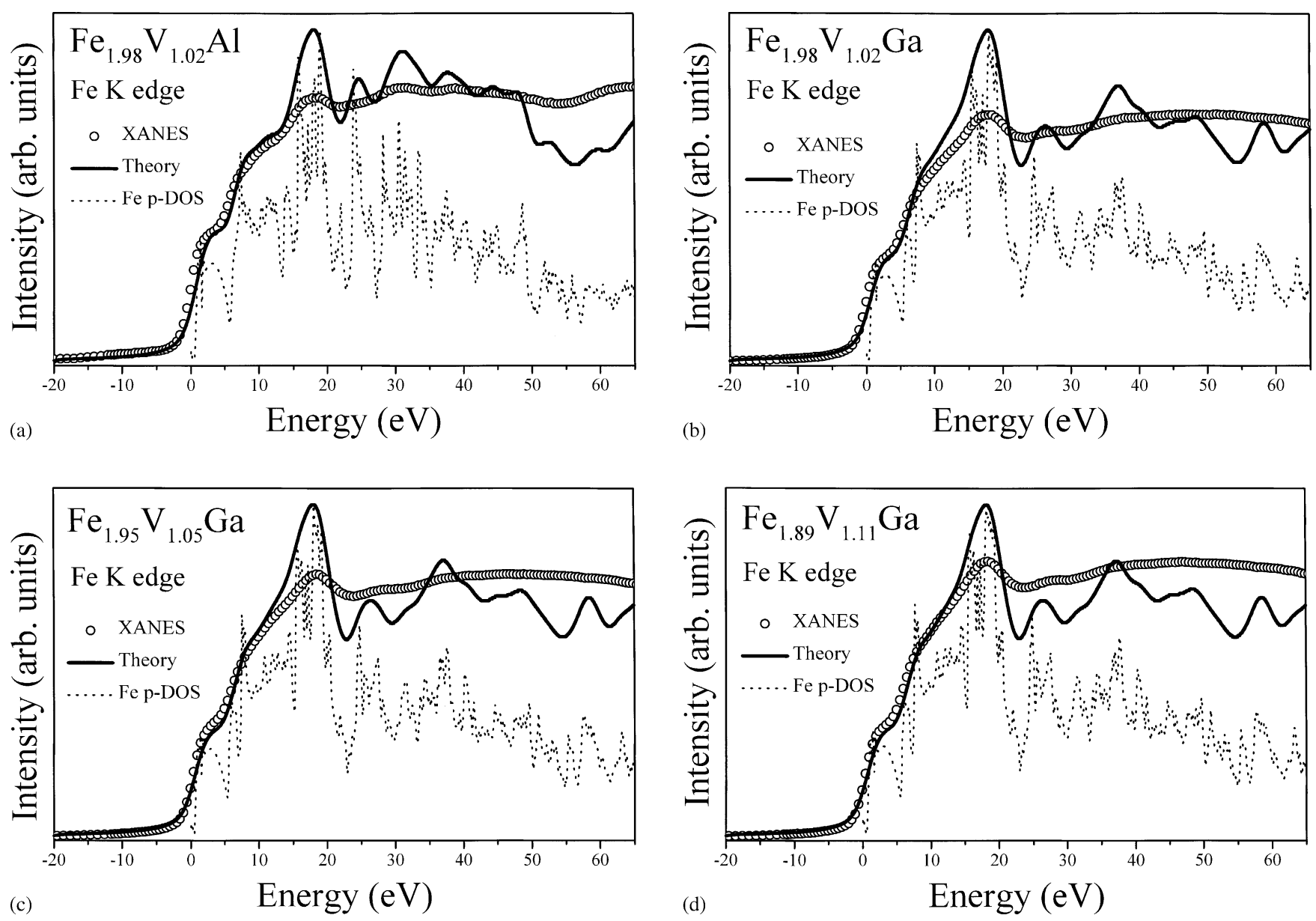

Fig. 3. The experimental $(\bigcirc)$ and theoretical (-) Fe K-edge XANES spectra for (a) $\mathrm{Fe}_{1.98} \mathrm{~V}_{1.02} \mathrm{Al}$, (b) $\mathrm{Fe}_{1.98} \mathrm{~V}_{1.02} \mathrm{Ga}$, (c) $\mathrm{Fe}$ 1.95 $\mathrm{V}_{1.05} \mathrm{Ga}$, and (d) $\mathrm{Fe}_{1.89} \mathrm{~V}_{1.11} \mathrm{Ga}$. Also shown is the $\mathrm{Fe} \mathrm{p}$ partial DOS $(\cdots)$ for these alloys. 

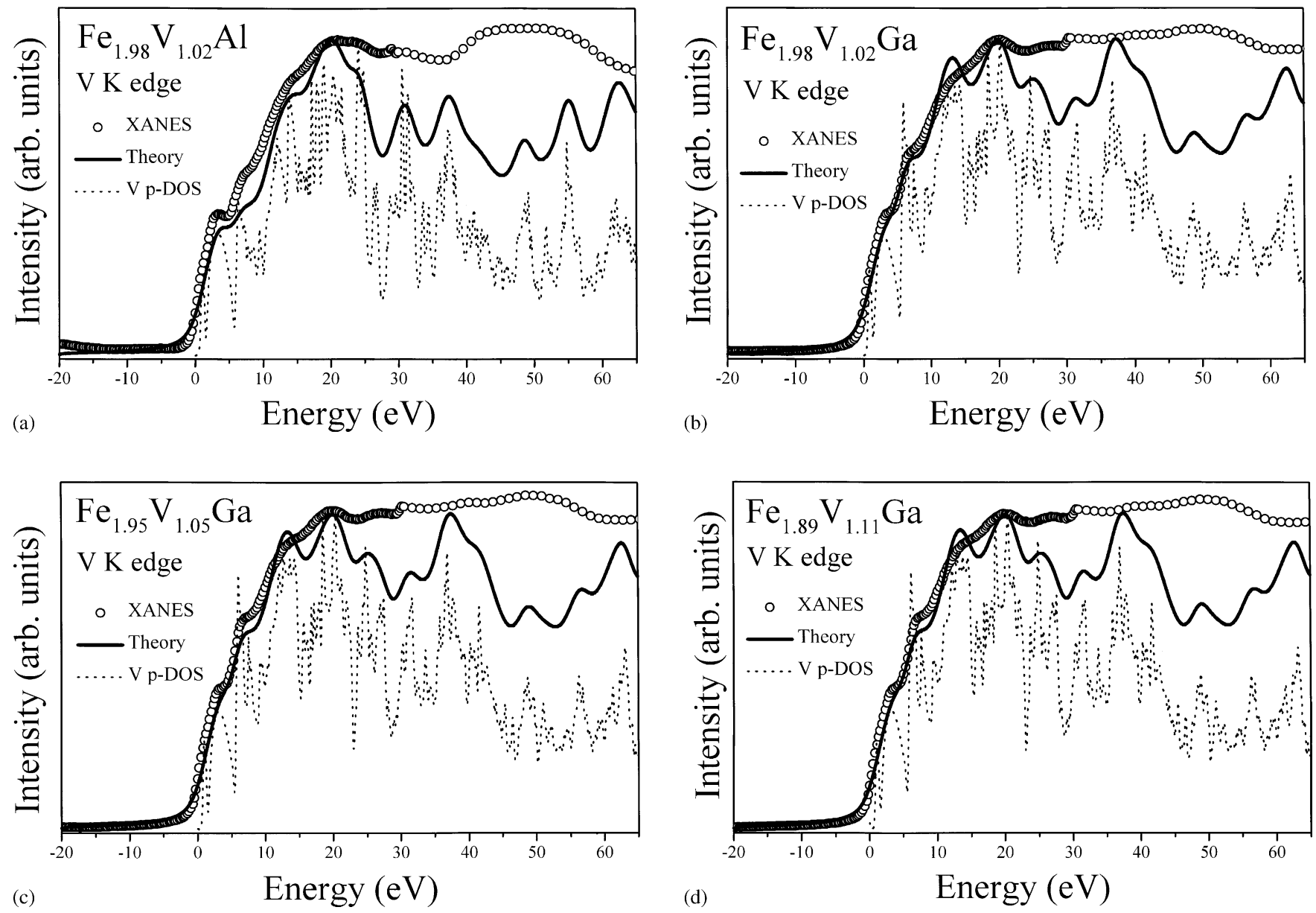

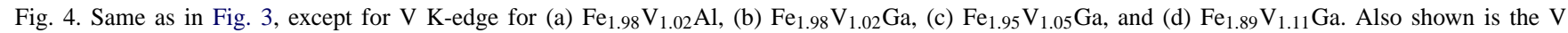
$\mathrm{p}$ partial DOS $(\cdots)$ for these alloys.

correspond to the inflection points of the Fe and V K-edge absorption thresholds (7112.1 and $5465 \mathrm{eV}$, respectively). The experimental data were normalized to the theoretical spectra at the Fe or V K-edge peak. The white-line positions and intensities and the absorption peaks above the white-line energies are well reproduced in the theoretical spectra. Discrepancies in peak positions and peak intensities between theoretical and experimental spectra might be due to the use of the GGA approximation in density functional theory and to the neglect of the core-hole effects. Another source of error in peak positions is the self-energy correction between GGA and more sophisticated methods, such as GW [24]. The decrease in peak height after the maxima in the theoretical XANES spectra is due to the finite-sized, linearized energy-dependent basis sets in the muffin-tin spheres used in the present calculation. As for the source of the discrepancy in peak width, the hot-electron lifetime is strongly energy dependent so that it mostly damps peaks about $20 \mathrm{eV}$ above the absorption edge.

The calculated total $n\left(E_{\mathrm{F}}\right)$ values for $\mathrm{Fe}_{2} \mathrm{VAl}, \mathrm{Fe}_{2} \mathrm{VGa}$, $\mathrm{Fe}_{2-x} \mathrm{~V}_{1+x} \mathrm{Al}$, and $\mathrm{Fe}_{2-x} \mathrm{~V}_{1+x} \mathrm{Ga}(x=0.02,0.05$, and 0.11 ) are listed in the fourth column in Table 2, and the site-decomposed $n\left(E_{\mathrm{F}}\right)$ values are listed in Table 3 . The cal- culated $n\left(E_{\mathrm{F}}\right)$ values for $\mathrm{Fe}_{2} \mathrm{VAl}$ and $\mathrm{Fe}_{2} \mathrm{VGa}$ are 0.18 and 0.28 states/eV cell, respectively, and the major contribution to the higher $n\left(E_{\mathrm{F}}\right)$ value for $\mathrm{Fe}_{2} \mathrm{VGa}$ comes from that of the $\mathrm{V}$ sites in this compound, as can be seen in Table 3. Our calculated total and partial $n\left(E_{\mathrm{F}}\right)$ values for $\mathrm{Fe}_{2} \mathrm{VAl}$ and $\mathrm{Fe}_{2} \mathrm{VGa}$ were published previously and compared with those obtained from other theoretical calculations and nuclear magnetic resonance or specific-heat measurements [6]. The calculated total $n\left(E_{\mathrm{F}}\right)$ values increase sharply as $\mathrm{V}$

Table 3

Density of states at the Fermi energy $n\left(E_{\mathrm{F}}\right)$ (states/eV cell) at different atomic sites for $\mathrm{Fe}_{2} \mathrm{VAl}, \mathrm{Fe}_{2} \mathrm{VGa}, \mathrm{Fe}_{2-x} \mathrm{~V}_{1+x} \mathrm{Al}$, and $\mathrm{Fe}_{2-x} \mathrm{~V}_{1+x} \mathrm{Ga}(x=$ $0.02,0.05$, and 0.11 )

\begin{tabular}{lllllll}
\hline Material & $\mathrm{Fe}(\mathrm{I})$ & $\mathrm{Fe}(\mathrm{II})$ & $\mathrm{V}$ & $\mathrm{Al}(\mathrm{Ga})$ & Interstitial & Total \\
\hline $\mathrm{Fe}_{2} \mathrm{VAl}$ & 0.096 & & 0.062 & 0.007 & 0.017 & 0.18 \\
$\mathrm{Fe}_{1.98} \mathrm{~V}_{1.02} \mathrm{Al}$ & 0.270 & 0.272 & 0.028 & 0.020 & 0.039 & 0.629 \\
$\mathrm{Fe}_{1.95} \mathrm{~V}_{1.05} \mathrm{Al}$ & 0.793 & 0.804 & 0.054 & 0.039 & 0.086 & 1.776 \\
$\mathrm{Fe}_{1.89} \mathrm{~V}_{1.11} \mathrm{Al}$ & 1.448 & 1.514 & 0.103 & 0.065 & 0.157 & 3.287 \\
$\mathrm{Fe}_{2} \mathrm{VGa}$ & 0.119 & & 0.128 & 0.008 & 0.024 & 0.28 \\
$\mathrm{Fe}_{1.98} \mathrm{~V}_{1.02} \mathrm{Ga}$ & 0.182 & 0.183 & 0.030 & 0.013 & 0.028 & 0.436 \\
$\mathrm{Fe}_{1.95} \mathrm{~V}_{1.05} \mathrm{Ga}$ & 0.388 & 0.394 & 0.038 & 0.024 & 0.05 & 0.894 \\
$\mathrm{Fe}_{1.89} \mathrm{~V}_{1.11} \mathrm{Ga}$ & 1.528 & 1.596 & 0.102 & 0.057 & 0.148 & 3.431 \\
\hline
\end{tabular}


doping increase from 0.02 to 0.11 for $\mathrm{Fe}_{2} \mathrm{VAl}$ and $\mathrm{Fe}_{2} \mathrm{VGa}$. This is because about 34 and $46 \%$ of the total $n\left(E_{\mathrm{F}}\right)$ for $\mathrm{Fe}_{2} \mathrm{VAl}$ and $\mathrm{Fe}_{2} \mathrm{VGa}$, respectively, comes from the $\mathrm{V}$ contribution. The former is close to that $(42 \%)$ calculated for $\mathrm{Fe}_{2} \mathrm{VAl}$ previously [25]. However, for the nonstoichiometric compounds, only a few percent and close to $90 \%$ of the total electronic states at $E_{\mathrm{F}}$ arises from $\mathrm{V}$ and $\mathrm{Fe}(\mathrm{I})+\mathrm{Fe}$ (II) atoms, respectively (see Table 2). The $n\left(E_{\mathrm{F}}\right)$ values at the $\mathrm{Fe}(\mathrm{I})$ sites are smaller than those at the $\mathrm{Fe}(\mathrm{II})$ sites.

The calculated bulk modulus (B) values for these materials are listed in the last column in Table 2. The B value for the $\mathrm{Al}$ compounds decreases slightly as $\mathrm{V}$ content increases; while it is essentially a constant for the Ga compounds. To our knowledge, there are no experimental B values reported for these materials.

\subsection{Ni $\mathrm{L}_{2,3}$-edge XANES spectra of $\mathrm{Ni}_{3} \mathrm{Al}, \mathrm{Ni}_{3} \mathrm{Ga}$, $\mathrm{Ni}_{3} \mathrm{In}$, and $\mathrm{NiGa}$}

The experimental (open circles) and theoretical (solid or dashed lines) XANES spectra of $\mathrm{Ni}_{2,3}$ edges for paramagnetic $\mathrm{Ni}_{3} \mathrm{Al}, \mathrm{Ni}_{3} \mathrm{Ga}, \mathrm{Ni}_{3} \mathrm{In}$, and $\mathrm{NiGa}$ are displayed in
Fig. 5a-d, respectively. The theoretically-calculated FLAPW and MS spectra are shown in the lower and upper part, respectively, of each figure. The zero energy corresponds to the inflection point of the $\mathrm{Ni}_{3}$ absorption edge $(852.7 \mathrm{eV})$. The experimental data were normalized to the theoretical spectra at the $\mathrm{Ni} \mathrm{L}_{3}$-edge peak except for Fig. 5d curve (I) of NiGa, whose experimental XANES spectrum was normalized to the theoretical one at the $\mathrm{Ni}_{2}$-edge peak. We note that $\mathrm{Ni}_{3} \mathrm{Al}, \mathrm{Ni}_{3} \mathrm{Ga}$, and $\mathrm{Ni}_{3} \mathrm{In}$ have the cubic $\mathrm{L}_{2}$ structure, while $\mathrm{NiGa}$ has the $\mathrm{B} 2$ structure. It was also reported [26] that $\mathrm{Ni}_{3} \mathrm{In}$ has the ordered $\mathrm{D}_{19}$ structure isotypic with $\mathrm{Ni}_{3} \mathrm{Sn}$. However, the $\mathrm{Ni} \mathrm{L}_{2,3}$ XANES spectrum of $\mathrm{Ni}_{3} \mathrm{In}$ calculated with the MS theory using this latter structure resulted in a much worse agreement with the experimental spectrum than using the cubic $\mathrm{L1}_{2}$ structure for $\mathrm{Ni}_{3} \mathrm{In}$ [11]. Moreover, calculation using FLAPW theory predicted that nonmagnetic $\mathrm{Ni}_{3}$ In favors energetically the $\mathrm{D}_{22}$ structure rather than the $\mathrm{Ll}_{2}$ structure, while ferromagnetism would make the $\mathrm{L1}_{2}$ structure slightly lower in energy than the $\mathrm{D}_{22}$ structure [16]. Thus, in Fig. 5c, the three structures $\mathrm{L1}_{2}, \mathrm{DO}_{22}$, and $\mathrm{D}_{19}$ for $\mathrm{Ni}_{3}$ In are used in the FLAPW theory, while only the $\mathrm{L}_{2}$ structure is used for the MS theory.

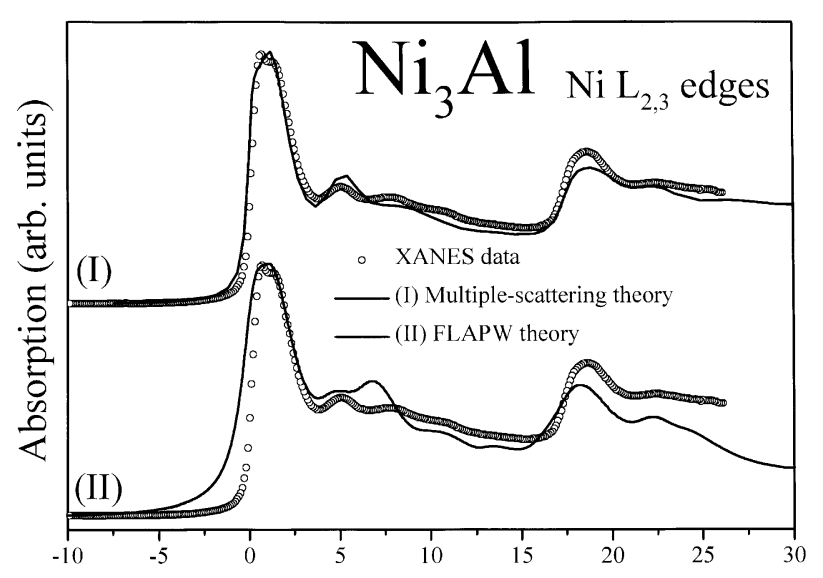

(a)

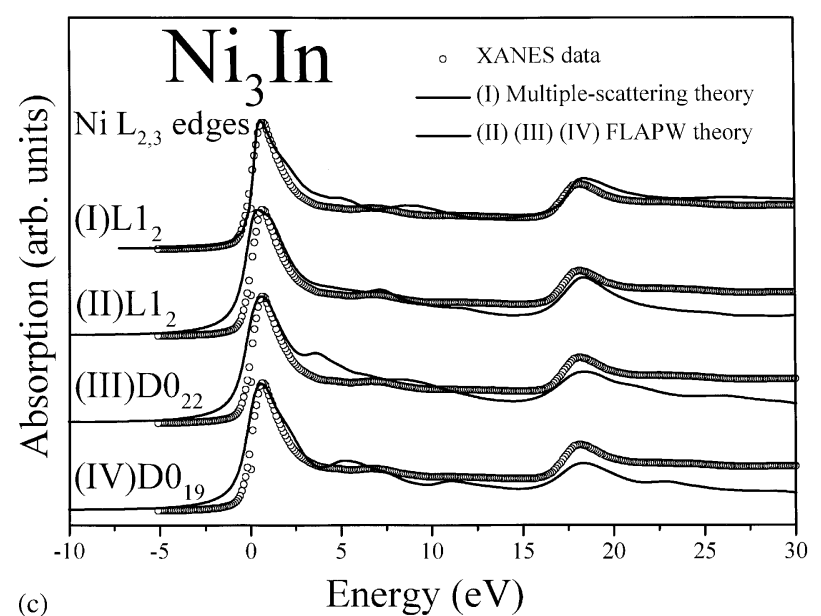

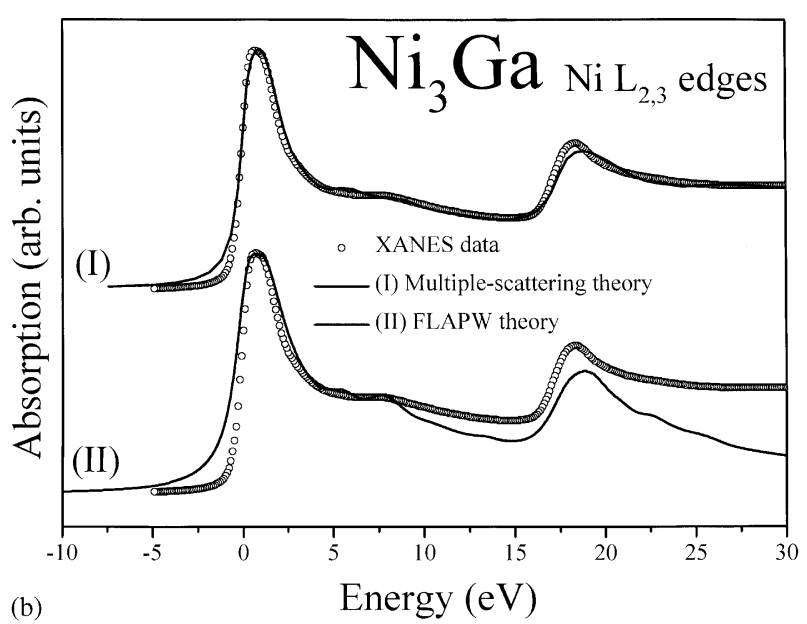

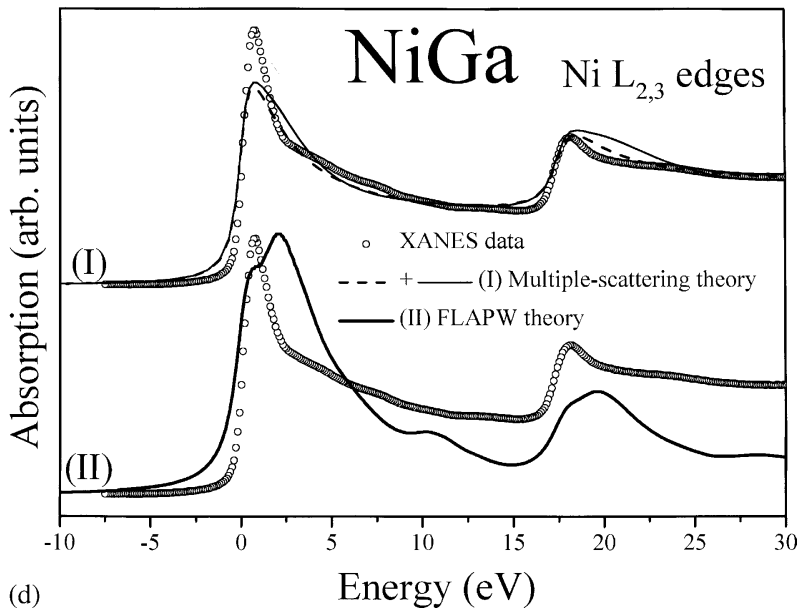

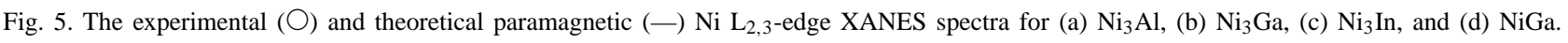


For NiGa, the calculated spectrum with and without multiple scattering is shown as solid and dashed line, respectively, in Fig. 5d. For other three compounds, the spectra are calculated with inclusion of multiple scattering, since without it their theoretical spectra possess no small features above the $\mathrm{Ni}_{3}$ white line.

Overall, we have a reasonable good agreement between theoretical and experimental XANES spectra for $\mathrm{Ni}_{3} \mathrm{Al}$ and $\mathrm{Ni}_{3} \mathrm{Ga}$. The decrease in peak height roughly $10 \mathrm{eV}$ above the $\mathrm{Ni} \mathrm{L}_{3}$ edge for $\mathrm{Ni}_{3} \mathrm{Al}$ and $\mathrm{Ni}_{3} \mathrm{Ga}$ is due to the finite-sized, linearized energy-dependent basis sets in the muffin-tin spheres used in the FLAPW calculation. Better agreement with experimental XANES spectra, especially for the $\mathrm{Ni}_{2}$ edge, is found for the spectra calculated by the MS method. We note that the peak energy of the $\mathrm{Ni}_{2}$ edge calculated by the FLAPW method for $\mathrm{Ni}_{3} \mathrm{Al}$ and $\mathrm{Ni}_{3} \mathrm{Ga}$ is lower by $0.3 \mathrm{eV}$ and higher by $0.7 \mathrm{eV}$ than the respective experimental values. We also note that the present experimental XANES spectra for $\mathrm{Ni}_{3} \mathrm{Al}$ and $\mathrm{Ni}_{3} \mathrm{Ga}$ are different from those reported previously $[9,10]$. Considering the agreement between present experimental and theoretical spectra, we suspect that previous XANES spectra for these two materials are not correct because the sample surfaces were not cleaned well. For $\mathrm{Ni}_{3} \mathrm{In}$, the agreement between theoretical FLAPW and experimental XANES spectra is best for the $\mathrm{L}_{2}$ structure, good for the $\mathrm{D}_{19}$ structure, and fair for the $\mathrm{D}_{22}$ structure. This observation is different from that found for the Ni K-edge XANES spectra for these three structures, where the $\mathrm{D}_{22}$ structure possesses the best agreement between the theoretical and experimental spectra [16]. We note that the difference in the Ni K-edge XANES spectra for the three structures of $\mathrm{Ni}_{3} \mathrm{In}$ is quite small for a clear identification of which structure is the best one. Both the FLAPW- and MS-calculated XANES spectra for the $\mathrm{L}_{2}$ structure of $\mathrm{Ni}_{3} \mathrm{In}$ agree well with the experimental one. However, the $6.0 \mathrm{eV}$ peak above the $\mathrm{Ni}_{3}$ edge of $\mathrm{Ni}_{3}$ In is better reproduced by the FLAPW method than the MS method. This means that although the MS method is better than the FLAPW method in calculating the high-energy $\mathrm{L}_{2}$ peak for these compounds, the $\mathrm{L}_{3}$-edge feature is better reproduced by the FLAPW method due to the use of full potential. All major features of the experimental absorption peaks, as well as white-line positions and intensities, are well reproduced in the theoretical XANES spectra for $\mathrm{Ni}_{3} \mathrm{Al}, \mathrm{Ni}_{3} \mathrm{Ga}$, and $\mathrm{Ni}_{3} \mathrm{In}$. For example, the theoretical $\mathrm{Ni} \mathrm{L}_{2,3}$-edge XANES spectra for $\mathrm{Ni}_{3} \mathrm{Al}$ roughly reproduce the three experimental peaks at 4.2, 7.1, and $9.5 \mathrm{eV}$ above the $\mathrm{Ni} \mathrm{L}_{3}$ white line. The same features are present in the calculated $\mathrm{Ni} \mathrm{L}_{2,3}$-edge XANES spectra for $\mathrm{Ni}_{3} \mathrm{In}$, though less pronounced and less agreement with the experimental peak positions at 4.5, 6.0, and $10.0 \mathrm{eV}$ above the $\mathrm{Ni}_{3}$ white line. Another source of error in peak positions comes from the use of the GGA approximation in the FLAPW method [24]. As for the source of the discrepancy in peak width, the hot-electron lifetime is strongly energy dependent so that it mostly damps peaks about $20 \mathrm{eV}$ above the absorption edge. Small discrepancies in peak positions and intensities in the MS calculation might be due to the use of muffin-tin approximation for the potentials. As shown in Fig. 5d (curve I), the MS theory underestimates the $\mathrm{Ni}_{3}$ peak intensity of $\mathrm{NiGa}$ by about $20 \%$, and the XANES spectrum calculated without using multiple scattering is in better agreement with the experimental data than that calculated with the multiple scattering included. However, compared with the XANES spectrum of NiGa calculated by the FLAPW method, the MS calculation seems more suitable in calculating the electronic structures of materials with high structural disorder like NiGa. The disagreement between theoretical and experimental XANES spectra found for NiGa is caused by high concentration of anti-structure defects $(0.75$ at. \%) present in the sample, [27] which was not considered in the FLAPW method and was not treated adequately in the MS method.

\section{Conclusions}

The electronic structures of $\mathrm{Fe}_{3} \mathrm{Al}, \mathrm{Fe}_{2-x} \mathrm{~V}_{1+x} \mathrm{Al}, \mathrm{Fe}_{2-x}$ $\mathrm{V}_{1+x} \mathrm{Ga}(x=0,0.02,0.05$, and 0.11$), \mathrm{Ni}_{3} \mathrm{Al}, \mathrm{Ni}_{3} \mathrm{Ga}, \mathrm{Ni}_{3} \mathrm{In}$, and $\mathrm{NiGa}$ were studied jointly by XANES measurements and by theoretical analysis using the FLAPW and MS methods. The experimental XANES spectra were measured at the $\mathrm{Fe}, \mathrm{V}$, and $\mathrm{Ni}_{2,3}$ edges and the $\mathrm{Fe} \mathrm{K}$ edge. The experimental K-edge XANES features for the Fe compounds and alloys reflect the Fe- and V-p unoccupied DOS, and their $n\left(E_{\mathrm{F}}\right)$ values at different atomic sites are calculated. Except for $\mathrm{NiGa}$, a reasonable good agreement between theory and experiment was found for these materilas. The disagreement between experimental and theoretical XANES spectra found for $\mathrm{NiGa}$ is caused by high concentration of anti-structure defects present in the sample.

\section{Acknowledgements}

We thank the staff of NSRRC for help in data taking, C.S. Lue for supplying the Fe compounds and alloys, and A.I. Nesvizhskii for the MS calculation. This work was partially supported by grants from the National Science Council, Taiwan, ROC.

\section{References}

[1] C.-S. Lue, Y.-K. Kuo, Phys. Rev. B 66 (2002) 085121, references therein.

[2] Y. Nishino, H. Kato, M. Kato, U. Mizutani, Phys. Rev. B 63 (2001) 233303, references therein.

[3] A. Bansil, S. Kaprzyk, P.E. Mijnarends, J. Tobola, Phys. Rev. B 60 (1999) 13396, references therein.

[4] G.Y. Guo, G.A. Botton, Y. Nishino, J. Phys.: Condens. Matter 10 (1998) L119.

[5] T. Sands, Appl. Phys. Lett. 52 (1988) 197.

[6] L.-S. Hsu, Y.-K. Wang, G.Y. Guo, C.S. Lue, Phys. Rev. B 66 (2002) 205203.

[7] L.-S. Hsu, Y.-K. Wang, G.Y. Guo, Nucl. Instrum. Methods Phys. Res. B 199 (2003) 200. 
[8] L.-S. Hsu, K.-L. Tsang, S.-C. Chung, in: L.J. Terminello, S.M. Mini, H. Ade, D.L. Perry (Eds.), Applications of Synchrotron Radiation Techniques to Materials Science III, MRS Symposia Proceedings No. 437, Materials Research Society, Pittsburgh, 1996, p. 53.

[9] W.F. Pong, K.P. Lin, Y.K. Chang, M.-H. Tsai, H.H. Hsieh, J.Y, Pieh, P.K. Tseng, J.F. Lee, L.-S. Hsu, J. Synchrotron Rad. 6 (1999) 731.

[10] Y.K. Chang, K.P. Lin, W.F. Pong, M.-H. Tsai, H.H. Hsieh, J.Y. Pieh, P.K. Tseng, J.F. Lee, L.-S. Hsu, J. Appl. Phys. 87 (2000) 1312.

[11] L.-S. Hsu, A.I. Nesvizhskii, J. Phys. Chem. Solids 62 (2001) 1103.

[12] A.N. Mansour, A. Dmitrienko, A.V. Soldatov, Phys. Rev. B 55 (1997) 15531.

[13] L.-S. Hsu, Y.-K. Wang, G.Y. Guo, J. Appl. Phys. 92 (2002) 1419.

[14] G.Y. Guo, Y.-K. Wang, L.-S. Hsu, J. Magn. Magn. Mater. 239 (2002) 91.

[15] L.-S. Hsu, K.-L. Tsang, S.-C. Chung, J. Magn. Magn. Mater. 177-181 (1998) 1031.

[16] G.Y. Guo, Y.-K. Wang, L.-S. Hsu, Phys. Rev. B 66 (2002) 054440.

[17] D.A. Muller, S. Subramanian, P.E. Batson, S.L. Sass, J. Silcox, Phys. Rev. Lett. 75 (1995) 4744.

[18] D.A. Muller, D.J. Singh, J. Silcox, Phys. Rev. B 57 (1998) 8181.

[19] L.-S. Hsu, R.S. Williams, J. Phys. Chem. Solids 55 (1994) 305.
[20] P. Blaha, K. Schwarz, G.K.H. Madsen, D. Kvasnicka, J. Luitz, WIEN2K, An Augmented Plane Wave + Local Orbitals Program for Calculating Crystal Properties, Techn. University Wien, Austria, 2001.

[21] A.L. Ankudinov, B. Ravel, J.J. Rehr, S.D. Conradson, Phys. Rev. B 58 (1998) 7565.

[22] L.-S. Hsu, G.Y. Guo, C.-J. Chen, M.-D. Lan, J.-F. Lee, in: P.G. Allen, S.M. Mini, D.L. Perry, S.R. Stock (Eds.), Applications of Synchrotron Radiation Techniques to Materials Science VI, MRS Symposia Proceedings No. 678, Materials Research Society, Pittsburgh, 2001, pp. EE8.5.1-EE8.5.6.

[23] L.-S. Hsu, Y.-K. Wang, G.Y. Guo, Y.-J. Huang, M.-D. Lan, in: V. Tikare, E.A. Olevsky, A. Zavaliangos (Eds.), Modeling and Numerical Simulation of Materials Behavior and Evolution, MRS Symposia Proceedings No. 731, Materials Research Society, Pittsburgh, 2002, pp. 301-306.

[24] P. Horsch, W. von der Linden, W.-D. Lukas, Solid State Commun. 62 (1987) 359.

[25] R. Weht, W.E. Pickett, Phys. Rev. B 58 (1998) 6855.

[26] W. Pearson (Ed.), Handbook of Lattice Spacings and Structures of Metals, Pergamon, New York, 1958.

[27] L.-S. Hsu, Y.D. Yao, Y.Y. Chen, Mod. Phys. Lett. B 11 (1997) 407. 